\title{
A 3-year investigation into the incidence and nature of cricket injuries in elite South African schoolboy cricketers
}

\author{
Richard A Stretch (D Phil) \\ Chris Trella (BA Hons) \\ Nelson Mandela Metropolitan University, Port Elizabeth, South Africa \\ Correspondence to: Richard Stretch (Richard.Stretch@nmmu.ac.za)
}

\begin{abstract}
Objectives. Injury surveillance is fundamental to preventing and reducing the risk of injury. The aim of this study is to determine the incidence of the injuries sustained by elite schoolboy cricketers over three seasons (2007 - 2008, 2008 - 2009, 2009 2010) to identify possible risk factors.

Methods. Sixteen provincial age-group cricket teams (Under 15 , Under 17 and Under 18) competing in national age-group tournaments were asked to complete questionnaires to obtain the following information for each injury: (i) anatomical site; (ii) month; (iii) cause; (iv) whether it was a recurrence of a previous injury; $(v)$ whether the injury had reoccurred again during the season; and ( $v i$ ) biographical data. Injuries were grouped according to the anatomical region injured. All players were requested to respond, irrespective of whether an injury had been sustained. The Sample Statistical Analysis System (SAS) was used to compute univariate statistics and frequency distributions. Of the 1292 respondents 366 (28\%) sustained a total of 425 injuries. The U15 and U17 groups sustained 166 (39\%) and 148 (35\%) injuries, respectively, more than the 111 injuries sustained by the U18 group (26\%). These injuries were predominantly to the lower (46\%) and upper (35\%) limbs and occurred primarily during 1 -day matches $(31 \%)$, practices $(27 \%)$ and with gradual onset (21\%). The primary mechanism of injury was bowling (45\%) and fielding, including running to field the ball (33\%). Forty-two lumbar muscle strains, 18 hamstring strains, 17 spondylolisthesis and 17 ankle sprains occurred. The injuries were acute (50\%), chronic (42\%) and acute-on-chronic (8\%), with $24 \%$ and $46 \%$ being recurrent injuries from the previous and current seasons, respectively.

Results. Similar injury patterns occurred in studies of adult cricketers, with slight differences in the nature and incidence of injuries found for the various age groups. The U15 group sustained less serious injuries which resulted in them not being able to play for between 1 - 7 days (54\%), with more injuries occurring in the pre-season period (28\%) than the other groups. The U17 group sustained the most lumbar muscle strains $(n=23)$, while the U18 group sustained more serious injuries with $60 \%$ of the injuries resulting in them not being able to play for 8 or more days.

Conclusion. Young fast-bowlers of all ages remain at the greatest risk of injury while slight differences in the nature and incidence of injuries occurred in the different age groups. It is recommended that cricket administrators and coaches need to implement an educational process of injury prevention and management.
\end{abstract}

\section{Introduction}

Injury surveillance is fundamental for preventing and reducing the risk of injury. As a result injuries in adult cricketers have been well researched over the years with long-term injury surveillance being carried out in Australia, ${ }^{1}$ England ${ }^{2}$ and South Africa. ${ }^{3}$ The findings of these studies report that bowlers were at the greatest risk of injury, sustaining between $40 \%$ and $45 \%$ of the injuries, followed by fielders, including wicket-keepers (25 - 33\%) and then batsmen (17 - 21\%). These injuries were predominantly to the lower limbs (45 - 49\%), back and trunk (18 - 23\%) and upper limbs (23 - 29\%). The injuries were predominantly sustained during matches (52 - 58\%) and occurred during the early part of the season (35\%). Between $65 \%$ and $92 \%$ of the injuries sustained were new injuries, with between $8 \%$ and $22 \%$ being recurrent injuries from the previous season and $12 \%$ recurring in the same season. Of the injuries, $65 \%$ were of an acute nature, with $23 \%$ chronic and $12 \%$ of an acute-on-chronic nature. The primary mechanism of injury was the delivery and follow-through in bowling (25\%), running, diving, catching and throwing (23\%) and overuse (17\%). Soft-tissue injuries were the most common, with the most likely sites to be injured being the thigh and calf (25\%), fingers (14\%) and lumbar spine (11\%). Similarly, in a study on West Indies cricketers $68 \%$ of injuries occurred during matches, with bowlers (46\%) and batsmen (40\%) more likely to sustain muscle (26\%), ligament (12\%), stress fractures (12\%) and fractures (10\%). ${ }^{4}$

While injuries in adult cricketers have been well documented in the literature, there remains a paucity of literature on injuries, injury patterns and risk factors in young cricketers. A study by Stretch ${ }^{5}$ reported that the high seasonal incidence of injuries to schoolboy cricketers was similar to that of a previous study on club and provincial cricketers. ${ }^{6}$ The overall seasonal incidence of injury was found to be $49 \%$, with the most common site of injury the back and trunk (33\%), upper limbs (25\%) and the lower limbs (23\%). Bowlers (47\%) were at greater risk of injury than the batsmen (30\%) and fielders (23\%). The injuries occurred equally during matches (46\%) and practices (47\%), with $30 \%$ being recurrent injuries from the previous season and $37 \%$ of the new injuries recurring during the same season.

In an intervention study aimed at reducing the risk of injury to fast-bowlers, Dennis et al. ${ }^{7}$ monitored 12- and 17-year-old cricketers playing club and district cricket over a season to evaluate the recommended bowling workloads in young cricketers. ${ }^{7}$ The findings revealed a relationship between a high bowling workload and injury. Of the 44 bowlers, 11 reported over-bowling-related injuries, with 7 sustaining back-related injuries. The injured bowlers bowled more frequently and had shorter rest periods between bowling sessions than the uninjured. The bowlers with an average of more than 3.5 rest days between bowling were at significantly less risk of injury than those with an average of less than 3.5 rest days. The results showed 
Table 1. Injuries for the U15, U17 and U18 age groups

\begin{tabular}{|c|c|c|c|c|c|c|c|c|}
\hline & \multicolumn{2}{|c|}{ U15 } & \multicolumn{2}{|c|}{ U17 } & \multicolumn{2}{|c|}{ U18 } & \multicolumn{2}{|c|}{ Total } \\
\hline & $\#$ & $\%$ & $\#$ & $\%$ & $\#$ & $\%$ & $\#$ & $\%$ \\
\hline \multicolumn{9}{|l|}{ Players } \\
\hline No injuries & 281 & 66 & 279 & 69 & 306 & 76 & 866 & 70 \\
\hline Injured & 146 & 34 & 125 & 31 & 95 & 24 & 366 & 30 \\
\hline Injuries sustained & 166 & 39 & 148 & 35 & 111 & 26 & 425 & 100 \\
\hline One injury & 130 & 31 & 104 & 24 & 81 & 19 & 315 & 74 \\
\hline Two injuries & 24 & 6 & 38 & 9 & 24 & 6 & 86 & 20 \\
\hline Three injuries & 12 & 3 & 6 & 1 & 6 & 1 & 24 & 6 \\
\hline \multicolumn{9}{|c|}{ Season and number of injuries } \\
\hline 2008 & 32 & 8 & 18 & 3 & 32 & 8 & 82 & 19 \\
\hline One injury & 26 & & 16 & & 26 & & 68 & \\
\hline Two injuries & 6 & & 2 & & 6 & & 14 & \\
\hline Three injuries & - & & - & & - & & - & \\
\hline 2009 & 49 & 12 & 57 & 13 & 24 & 6 & 130 & 31 \\
\hline One injury & 42 & & 47 & & 18 & & 107 & \\
\hline Two injuries & 4 & & 10 & & 6 & & 20 & \\
\hline Three injuries & 3 & & - & & & & 3 & \\
\hline 2010 & 85 & 20 & 73 & 17 & 55 & 13 & 213 & 50 \\
\hline One injury & 62 & & 41 & & 37 & & 140 & \\
\hline Two injuries & 14 & & 26 & & 12 & & 52 & \\
\hline Three injuries & 9 & & 6 & & 6 & & 21 & \\
\hline
\end{tabular}

an increase in risk of injury for bowlers who bowled more than 50 deliveries per day and who bowled on average more than 2.5 days per week.

Bowling was the primary cause of injuries in a group of 196 elite schoolboy cricketers taking part in the 2004 national U19 Cricket Week. The primary mechanism of injury occurred during the delivery stride and follow-through when bowling at pace. Most of the injuries were first-time injuries ( $87 \%$ ) with $41 \%$ severe enough to prevent the players from practising or playing for more than 21 days. ${ }^{8}$

A total of 46 young fast-bowlers between the ages of 11 and 18 years were assessed with a view to determine the injury profile and associated risk factors during a season. ${ }^{9}$ Fifteen of the bowlers remained injury-free during the season, with the most common injury to the knee (41\%) and the lower back (37\%). The injuries occurred primarily during mid-season and were mainly strains (39\%). The results also indicated the multifactorial role that inadequate fitness, high bowling workloads and bowling techniques play in predisposing a young fast- bowler to risk of injury.

It is not appropriate to use the data from adult injury surveillance studies to design coaching and training programmes to reduce injuries in young cricketers. Thus, the aim of this study was to determine the seasonal incidence of injuries and possible risk factors sustained by elite schoolboy cricketers and to identify possible differences between players of different age groups.

\section{Method}

The sample consisted of provincial cricketers competing in three national age-group cricket tournaments (U15, U17 and U18). Ethics approval for this study was obtained from the Nelson Mandela Metropolitan University's ethics committee. A questionnaire was handed out to all the players by the team coach and they were required to complete the questionnaire, irrespective of whether an injury had been sustained or not. The questionnaire was designed to obtain the following information for each injury: (i) anatomical site; (ii) month; (iii) cause; (iv) whether it was a recurrence of a previous injury; ( $v$ ) whether the injury had reoccurred again during the season; and (vi) biographical data. As this study required the player to recall the injuries from the previous season it was dependent of his understanding and interpretation of his medical practitioner's diagnosis. No other medical records or records of other sports played were obtained.

An injury was defined as an injury that prevented a player from being fully available for selection for a match or which prevented the player from completing the match, with all injuries classified according to the OSICS injury classification system. ${ }^{10}$ For purposes of this survey the incidence of injury was expressed as a percentage of the total number of injuries recorded.

Injuries were grouped according to the anatomical region injured as follows: (i) head, neck and face; (ii) upper limbs; (iii) back and trunk; and (iv) lower limbs. Injuries were classified 
Table 2. Injury occurrence

\begin{tabular}{|c|c|c|c|c|}
\hline & U15 & U17 & U18 & Total \\
\hline & $\%$ & $\%$ & $\%$ & $\%$ \\
\hline \multicolumn{5}{|l|}{ Time of year when injured } \\
\hline Off-season (April - July) & 14 & 13 & 15 & 14 \\
\hline Pre-season (August - September) & 28 & 24 & 21 & 25 \\
\hline Season (October - March) & 58 & 63 & 64 & 61 \\
\hline \multicolumn{5}{|l|}{ Occurrence } \\
\hline First-time & 24 & 32 & 36 & 30 \\
\hline \multicolumn{5}{|l|}{ Recurrent injuries } \\
\hline Previous season & 25 & 23 & 24 & 24 \\
\hline Current season & 51 & 45 & 40 & 46 \\
\hline \multicolumn{5}{|l|}{ Injury occurrence } \\
\hline Warm-up & 7 & 11 & 2 & 7 \\
\hline Practice & 34 & 25 & 20 & 27 \\
\hline $20 / 20$ match & 3 & 3 & 3 & 3 \\
\hline 1-day match & 27 & 35 & 29 & 31 \\
\hline Gradually & 18 & 20 & 25 & 21 \\
\hline Other & 11 & 6 & 21 & 11 \\
\hline \multicolumn{5}{|l|}{ Chronicity } \\
\hline Acute & 49 & 54 & 47 & 50 \\
\hline Chronic & 43 & 38 & 46 & 42 \\
\hline Acute-on-chronic & 8 & 8 & 7 & 8 \\
\hline \multicolumn{5}{|l|}{ Time out of cricket } \\
\hline $1-3$ days & 33 & 30 & 27 & 31 \\
\hline 4 -7 days & 21 & 18 & 14 & 18 \\
\hline 8 - 14 days & 11 & 17 & 20 & 15 \\
\hline 15 - 21 days & 7 & 9 & 10 & 8 \\
\hline $21+$ days & 28 & 26 & 29 & 28 \\
\hline
\end{tabular}

according to whether they were sustained during batting, bowling, fielding (including catching and wicket-keeping), fitness training and 'other'. The time of the year when the injury occurred was recorded, with the off-season being the time of the year when no specific cricket practice or matches took place (April - July). The pre-season (August and September) was the part of the year when specific cricket training and practice was undertaken in preparation for the season and before the commencement of matches. The season (October - March) was defined as the period when matches were played.

In order to allow comparisons to be made between the phases of play during which the injuries were sustained, the number of injuries was expressed as a percentage of the total number of injuries sustained. Similarly, to allow comparisons to be made between the injuries sustained by the players in the various age groups, the number of injuries was expressed as a percentage of the number of injuries sustained in that particular age group.
Table 3. Injury per activity and mechanism

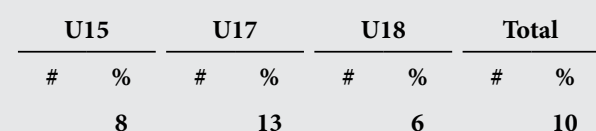

Batting

13

10

Overuse

Running between

wickets

Spiked while run-

ning

\begin{tabular}{|c|c|c|c|c|}
\hline Bowling & & & & \\
\hline $\begin{array}{l}\text { Run-up and } \\
\text { delivery }\end{array}$ & 61 & 52 & 40 & 153 \\
\hline Over-bowling & 20 & 9 & 7 & 36 \\
\hline
\end{tabular}

$\begin{array}{lllllll}\begin{array}{l}\text { Catching, fielding } \\ \text { and throwing }\end{array} & & 30 & 33 & 37 & 33 \\ \text { Running to slide } & 7 & & 12 & & & \end{array}$

$\begin{array}{lllll}\text { Running to slide } & 7 & 12 & 6 & 25 \\ \text { and field } & & & \end{array}$

$\begin{array}{lllll}\text { Running to catch/ } & 12 & 7 & 11 & 30 \\ \text { field }\end{array}$

Impact by ball $\quad 1 \quad 5 \quad 3$

$\begin{array}{lllll}\text { Catching ball } & 9 & 10 & 2 & 21\end{array}$

$\begin{array}{lllll}\text { Throwing } & 9 & 8 & 8 & 25\end{array}$

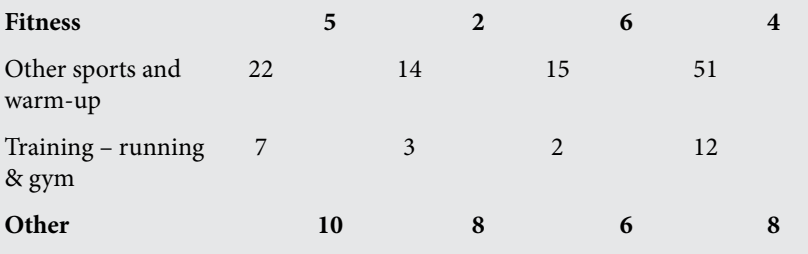

The Sample Statistical Analysis System (SAS) was used to compute univariate statistics and frequency distributions.

\section{Results}

Of the 1232 respondents 366 players sustained 425 injuries, with 315 players sustaining one injury, 43 players sustaining two and 8 players sustaining three injuries, with similar patterns found for the three age groups (Table 1). Of the 425 injuries sustained, the U15 sustained 166 (39\%) injuries, the U17 sustained 148 (35\%) injuries and the U18 groups sustained $111(26 \%)$ injuries.

The injuries occurred primarily during the season (61\%), with $25 \%$ occurring during the pre-season and $14 \%$ during the off-season (Table 2). Of the 425 injuries $24 \%$ and $46 \%$ were recurrent injuries from the previous and current seasons, respectively, while $30 \%$ of the injuries were first-time injuries. The injuries occurred primarily during 1-day matches (31\%), practice (27\%) and gradually (21\%). The U18 groups sustained fewer injuries as a result of practices than the other two groups. The injuries were acute (50\%), chronic (42\%) and acute-onchronic (8\%), with the injuries sustained by the U17 group more of an acute (54\%) than chronic (38\%) nature.

The length of time that the players were unable to train or play matches due to injuries showed similar results for the three groups (Table 2). 
Table 4. Regional distribution and diagnosis of injuries

\begin{tabular}{|c|c|c|c|c|c|c|c|c|}
\hline & \multicolumn{2}{|c|}{ U15 } & \multicolumn{2}{|c|}{ U17 } & \multicolumn{2}{|c|}{ U18 } & \multicolumn{2}{|c|}{ Total } \\
\hline & $\#$ & $\%$ & $\#$ & $\%$ & $\#$ & $\%$ & $\#$ & $\%$ \\
\hline \multicolumn{9}{|l|}{ Regional distribution } \\
\hline Body region: head & & 4 & & 4 & & 5 & & 4 \\
\hline Eye & - & & 2 & & - & & 2 & \\
\hline Unconscious & 1 & & 2 & & - & & 3 & \\
\hline Fracture & 2 & & 1 & & 3 & & 6 & \\
\hline Body region: upper limbs & & 25 & & 26 & & 21 & & 24 \\
\hline Dislocation & 5 & & 5 & & 2 & & 12 & \\
\hline Joint & 6 & & 1 & & 5 & & 12 & \\
\hline Fracture & 8 & & 2 & & 2 & & 12 & \\
\hline Muscle & 13 & & 17 & & 6 & & 36 & \\
\hline Body region: back and trunk & & 31 & & 34 & & 35 & & 33 \\
\hline Stress fracture & 14 & & 9 & & 10 & & 33 & \\
\hline Muscle & 30 & & 28 & & 20 & & 78 & \\
\hline Body region: lower limbs & & 40 & & 36 & & 39 & & 39 \\
\hline Tendon & 11 & & 5 & & 3 & & 19 & \\
\hline Ligament & 15 & & 14 & & 14 & & 43 & \\
\hline Muscle & 27 & & 23 & & 20 & & 70 & \\
\hline Joint & 11 & & 4 & & - & & 15 & 1 \\
\hline \multicolumn{9}{|l|}{ Diagnosis } \\
\hline Muscle strain & 44 & & 55 & & 33 & & 132 & 31 \\
\hline Sprain & 32 & & 26 & & 16 & & 74 & 17 \\
\hline Fracture & 11 & & 6 & & 9 & & 26 & 6 \\
\hline Stress fracture & 12 & & 14 & & 12 & & 38 & 9 \\
\hline Dislocation & 5 & & 7 & & 1 & & 13 & 3 \\
\hline Ruptures and tendinopathy & 7 & & 10 & & 7 & & 24 & 6 \\
\hline Periostitis & 2 & & 4 & & 1 & & 7 & 2 \\
\hline Lacerations and haematomas & 3 & & 2 & & 6 & & 11 & 3 \\
\hline Trigger points & 5 & & 1 & & - & & 6 & 1 \\
\hline Other trauma & 18 & & 6 & & 7 & & 31 & 7 \\
\hline Other & 27 & & 17 & & 19 & & 63 & 15 \\
\hline
\end{tabular}

Of the injuries, $31 \%$ were less severe with the players not being able to practise or play for 1 - 3 days, while the more serious injuries (28\%) resulted in the players not being able to practise or play for more than 21 days. A similar pattern was shown for the three age groups except that the injuries resulted in more of the U18 group not able to practise for 8 - 14 days and fewer were not able to practise or play for between 4 and 7 days.

The injuries occurred primarily when bowling (45\%) and fielding, including catching and running to field the ball (33\%) (Table 3). The U15 group showed a similar injury pattern to the total group, while the U17 players sustained more injuries while batting (13\%). The U18 group sustained fewer injuries while batting, but recorded the highest percentage $(37 \%)$ of injuries while fielding.
The injuries were predominantly to the lower limbs (39\%) and the back and trunk (33\%) (Table 4). The lower limb injuries were predominantly muscle $(n=70)$ and ligament $(n=43)$ injuries, while the back and trunk were predominantly muscle $(n=78)$ and stress fracture $(n=33)$ injuries. The 425 injuries were mainly muscle strains $(31 \%)$, acute sprains $(17 \%)$ and stress $(9 \%)$ and acute $(6 \%)$ fractures, with a similar pattern occurring for the three age groups (Table 4).

\section{Discussion}

The primary findings of this study are that there were some areas where the young cricketers showed similar injury patterns to the 
adult cricketers, particularly with regard to the bowlers being most susceptible to injury, while there were differences in other areas.

Similar to the findings of adult cricketers and the previous study on schoolboy cricketers, ${ }^{5,7-9}$ the fast-bowlers were at the greatest risk of injury. Back injuries to fast-bowlers are as a result of multiple factors, with abnormalities of the spine occurring at an early age, possibly aggravated by the trunk rotation in a mixed bowling technique ${ }^{11}$ and predispose the bowler to stress fractures which will be compounded through excessive bowling during the growth period when the spine is relatively immature. Similarly, the most common injuries were muscle strains and injuries to the lower limbs and more injuries occurring when playing matches than when practising.

When compared with the adult cricket injuries the young cricketers were at greater risk of injury to the back and trunk, with more of the injuries of a chronic nature. The greater risk of sustaining chronic overuse type of injuries to the back and trunk region in the young cricketer is a concern to all involved in cricket. While over the past number of years much effort has focused on educating coaches, administrators, parents and the young cricketer on the dangers associated with over-bowling, bowling with the mixed-actions and poor physical preparation, it would appear that there is some breakdown in the system if the young players sustain more stress fractures in the lower back than the adult cricketers. This needs to again be the focus of research to further identify factors that may predispose these young cricketers to injury. Given these results and the importance of not only the number of deliveries bowled per session, but the frequency of bowling, ${ }^{9}$ coaches need to ensure that the rest guidelines are correctly enforced and that the young players have adequate rest days.

Differences in the nature and incidence of injuries were found for the various age groups, with the $\mathrm{U} 15$ and $\mathrm{U} 17$ groups sustaining more injuries during practices and the injuries keeping them out of cricket for 4 - 7 days. The U17 players showed an increase in batting injuries. The U18 players sustained fewer injuries in practices and when batting, but more injuries when bowling. Also, the U18 cricketers sustained more injuries which resulted in them being out of the game for longer periods (8 - 14, $15-21$ and 21+ days).

Further, the comparison of the various age groups within the junior cricketers shows differences in some other areas. While the relatively older cricketers among the youth participants were at lower risk for injuries of an acute nature while batting, they showed greater risk of injury while fielding. Injuries in fielding have largely been as a result of hand and finger trauma from attempts to catch the ball, direct impacts to the body resulting from collision with the ground or other players. ${ }^{3,12,13}$ The development of one-day cricket and the increasing competitiveness of cricket at school level have resulted in fielding becoming as important a facet of the game as batting and bowling. This has resulted in the evolution of the sliding stop, where the player runs at pace after the ball and then slides on the hip and knee. As the ball is picked up in the right hand, the right foot engages the ground and the forward momentum of the slide brings the fielder upright and into a position to throw. The tactical benefits of this high-risk technique have not been adequately researched and should either be discouraged at school level or adequately coached to avoid injury. ${ }^{13}$

\section{Conclusion}

Slight differences in the nature and incidence of injuries were found for the various age groups with some similarities to the injury patterns described in studies on adult cricketers. Young fast-bowlers and fielders are at the greatest risk of injury with multi-factorial causes predisposing them to injury. The similar injury patterns to the young fast-bowlers to that of the adult fast-bowlers may be as a result of them following adult-type programmes for training, practices and matches. Players, coaches, medical professionals, parents and administrators involved with the development of young cricketers need to be aware that direct extrapolation of coaching and training programmes designed for adult players may not be appropriate for young cricketers.

Better management of coaching and training programmes, injuries and adequate recovery time after injury would ensure that the young bowlers are better prepared for the demands of fast-bowling and would further reduce the risk of injury and re-injury in these young cricketers.

\section{REFERENCES}

1. Orchard J, James T, Alcott E. Injuries in Australian cricket at first class level 1995/1996 to 2000/2001. Br J Sports Med 2002;36:270-275.

2. Leary T, White J. Acute injury incidence in professional county club cricketer (19851995). Br J Sports Med 2000;34:145-147.

3. Stretch RA, Venter DJL. Cricket injuries - a longitudinal study of the nature of injuries to South African cricketers. S Afr J Sports Med 2005;17(2):4-9.

4. Mansingh A, Harper L, Headley S, King-Mowatt J, Mansingh G. Injuries in West Indian Cricket 2003-2004. Br J Sports Med 2006;40:119-123.

5. Stretch RA. The incidence and nature of injuries in schoolboy cricketers. S Afr Med J 1995;85(11):1182-1184.

6. Stretch RA. The incidence and nature of injuries in club and provincial cricketers. S Afr Med J 1993;83(5):339-341.

7. Dennis RJ, Finch CF, Farhart PJ. Is bowling workload a risk factor for injury to Australian junior cricket fast bowlers? Br J Sports Med 2005;39:843-846.

8. Millsom NM, Barnard JG, Stretch RA. Seasonal incidence and nature of cricket injuries among elite South African schoolboy cricketers. S Afr J Sports Med 2007; 19(3):80-84.

9. Davies R, Du Randt R, Venter DJL, Stretch RA. Cricket: nature and incidence of fast-bowling injuries in elite, junior level and associated risk factors. S Afr J Sports Med 2008;20(4):115-118.

10. Orchard J, Newman D, Stretch R, Frost W, Mansingh A, Leipus A. Methods for injury surveillance in international cricket. J Sc Med Sport 2005;8(1):1-14.

11. Elliott BC, Davis JW, Khangure MS, Hardcastle P. Disc degeneration and the young fast bowler. Clin Biomech 1993;8(5):227-234

12. Corrigan AB. Cricket injuries. Austr Fam Phys 1984;13(8):558-562.

13. Von Hagen K, Roach R, Summers B. The sliding stop: a technique of fielding in cricket with a potential for serious knee injury. Br J Sports Med 2000;34:379-381. 